\title{
Efficacy of Lumiracoxib Versus Diclofenac Sodium in Pain Control Following Extraction of Impacted Lower Third Molar
}

\author{
Eficacia de Lumiracoxib Frente a Diclofenaco de Sodio en el Control del \\ Dolor Después de la Extracción de un Tercer Molar Inferior Impactado
}

\begin{abstract}
Giovanni Antonio Nícoli'; Nicolau Conte-Neto²; Juliana Álvares-Duarte Bonini-Campos ${ }^{3}$; Marisa Aparecida Cabrini-Gabrielli ${ }^{4} \&$ Valfrido Antonio Pereira-Filho ${ }^{4}$
\end{abstract}

NíCOLI, G. A.; CONTE-NETO, N.; CAMPOS, J. Á. D. B.; CABRINI-GABRIELLI, M. A. \& PEREIRA-FILHO, V. A. Efficacy of lumiracoxib versus diclofenac sodium in pain control following extraction of impacted lower third molar. Int. J. Odontostomat., 11(1):47-51, 2017.

ABSTRACT: The aim of this paper was to compare the efficacy of two different anti-inflammatory agents, Diclofenac $\left(\right.$ Deltaflogin ${ }^{\circledR}$ ) and Lumiracoxib (Prexige ${ }^{\circledR}$ ) in the control of postoperative pain that results from surgical removal of impacted lower third molars. Twenty adult patients from the Oral and Maxillofacial Surgery Division of the Araraquara Dentistry School, UNESP who presented bilateral impacted lower third molars were included in the study. Removal of the impacted teeth was performed in each side in different operative moments in a split mouth design for the study. The anti-inflammatory drugs evaluated were randomly administered on the first and second surgical procedures. The pain level was recorded using an analogical visual scale at 6, 24, 48 and 72 hours after surgical intervention. Both lumiracoxib $400 \mathrm{mg}$ and diclofenac $100 \mathrm{mg}$ are efficient for acute pain control after surgical removal of impacted lower third molars. However, lumiracoxib offered better pain control.

KEY WORDS: pain; third molars; anti-inflammatory agents.

\section{INTRODUCTION}

The inflammatory process represents a defensive response against different types of physical, chemical or biological aggression. However, exacerbated inflammatory reactions can produce destructive phenomena increasing tissue damage. One example is excessive liberation of proteolytic enzymes and free radicals by neutrophils. Thus, modulation of inflammation is important to reduce pain and edema. It also facilitates healing and increases local vascular support (Vane, 1979).

Postoperative pain is usually treated with analgesic and non-steroidal anti-inflammatory drugs (NSAIDs), such as ibuprofen, paracetamol (acetaminophen), nimesulide (De Menezes et al., 2010; Bailey et al., 2014), rofecoxib, celecoxib and lumiracoxib (Kellstein et al., 2004). Traditional NSAIDs are non-selective and prevent prostaglandin synthesis via inhibition of both cyclooxygenase-1 (COX-1) and cyclooxygenase-2 (COX-2). Otherwise, highly selective cox-2 inhibitors (coxibs) were introduced aiming to reduce or eliminate the risk of gastric complications associated to the use of traditional NSAIDS (Rafaniello et al., 2016).

The role of traditional NSAIDs in managing postoperative pain after oral surgery have been widely studied, especially diclofenac (Tuzuner-Oncul et al.,

${ }^{1}$ Scientific Initiation student- Oral and Maxillofacial Division, Araraquara Dentistry School, São Paulo State University- UNESP, Brazil.

${ }^{2}$ UFPA Federal University of Pará, School of Dentistry, Department of Oral Surgery, Augusto Correa Street, OI, 66075-110, Belem-Para/ Brasil.

${ }^{3}$ UNESP- Univ. Estadual Paulista, School of Dentistry, Department of Social Dentistry, Humaitá Street, 1680, 14801-903 Araraquara -São Paulo/Brazil.

${ }^{4}$ UNESP- Univ. Estadual Paulista, School of Dentistry, Department of Diagnosis and Surgery, Humaitá Street, 1680, 14801-903 Araraquara -São Paulo/Brazil. 
NícolI, G. A.; CONTE-NETO, N.; CAMPOS, J. Á. D. B.; CABRINI-GABRIELLI, M. A. \& PEREIRA-FILHO, V. A. Efficacy of lumiracoxib versus diclofenac sodium in pain control following extraction of impacted lower third molar. Int. J. Odontostomat., 11(1):47-51, 2017.

2011; Akbulut et. al., 2014). On the other hand, regarding to coxibs group, most of papers have focused in rofecoxib and celecoxib use. In this context, we proposed to compare the analgesic efficacy and tolerability of lumiracoxib, which is structurally distinct from other COX-2 selective inhibitors (Mangold et al., 2004), with diclofenac sodium after third molars surgery.

\section{MATERIAL AND METHOD}

The subjects were selected from a pool of patients referred to a Public Dentistry College between January and December 2007 for third molar evaluation. The Institutional Ethics Committee approved the present research and all subjects signed a free prior and informed consent (FPIC).

This study included twenty healthy, non-smoking patients without contraindications to oral surgery and not taking any medication that had indication for removal of bilateral impacted third molars with similar impaction and position. All patients were submitted to orthopantomographic radiograms and teeth were classified according to Winter's system (mesioangular, vertical, distoangular e horizontal positions) (Winter, 1926).

The patients were randomly assigned the following nonsteroidal anti-inflammatory drugs administered orally: Group 1: diclofenac sodium 100 mg (Deltaflogin ${ }^{\circledR}$ - Delta) tablets taken once per Day; Group 2: lumiracoxib 400 mg (Prexige ${ }^{\circledR}$ - Novartis) tablets taken once per day. Both drugs, kept in appropriate receptacles with a green or red label, so that neither the surgeon nor the patient new what drug was taken at a given moment, constructing a double blind condition.

The study followed a split mouth design. Thus, the teeth were removed and the drugs were administered at two different moments. When the right impacted molar was removed, one of the drugs was used, while the other was given to the same patient when the left molar was removed. The minimum interval between the removal of the first and the second impacted lower third molar was 15 days.

Intraoral antisepsis was performed with $0.12 \%$ chlorhexidine digluconate and extra-oral antisepsis with polyvinylpyrrolidone iodine. The nerve block of the inferior alveolar, lingual and buccal nerves was carried out using $2 \%$ mepivacaine with 1:100.000 adrenalin (Mepíadre, DFL Industria e Comércio S.A., Rio de Janeiro, RJ, Brazil).

The surgery to remove the lower third molar was made by the same surgeon and followed the standardized technique. Briefly, the same incision was used for both sides, and a mucoperiosteal flap was elevated. A 702 high-speed burr was used for ostectomy and sectioning the tooth under abundant irrigation with sterilized $0.9 \%$ physiological solution. After extraction bone irregularities were removed and the surgical cavity was thoroughly cleansed. Interrupted 4-0 silk sutures (Ethicon, Sao Paulo, Brazil) were used for closure.

All subjects were instructed to eat only soft food, and to abstain from mouth washing during the first 24 $\mathrm{h}$ and from brushing and flossing around the surgical area until suture removal (14 days post surgery). Furthermore, patients received orientation about local hemostatic measures, 24 hour limited activity and oral hygiene. Mouth rinses with $0.12 \%$ chlorhexidine digluconate were used until suture removal.

Postoperative pain was assessed by means of an analogical visual scale during four days after third molar surgery (6, 24, 48 and 72 hours), always after 6 hours from the drug intake (Huskisson, 1983). The scale consists of a $100 \mathrm{~mm}$ straight line, which allows quantification of the postoperative pain.

Data referring to pain levels were analyzed using the Friedman test. In the case of statistical significance the Fisher LSD test for multiple comparisons was used. To compare pain levels described after ingestion of the different drugs the Wilcoxon test was used. The significance level considered was $5 \%$. Calculations were performed using the SPSS statistical software package (SPSS Inc., Chicago, IL, USA).

\section{RESULTS}

No accidents or complications were recorded with surgical procedures and the extraction socket healed uneventfully. Furthermore, all subjects complied with the research protocol, performed the follow-up measures and no drug side effect was reported.

Age of the patients ranged from 18 to 32 years old (24.4 \pm 3.2$), 18$ were women. Operating time was 
NíCOLI, G. A.; CONTE-NETO, N.; CAMPOS, J. Á. D. B.; CABRINI-GABRIELLI, M. A. \& PEREIRA-FILHO, V. A. Efficacy of lumiracoxib versus diclofenac sodium in pain control following extraction of impacted lower third molar. Int. J. Odontostomat., 11(1):47-51, 2017.

Table I. Pain intensity scores over the study period for the diclofenac sodium grou.

\begin{tabular}{lllll}
\hline & \multicolumn{3}{c}{ Period } \\
& 6 hours & 24 hours & 48 hours & 72 hours \\
\hline Scores sum & 72.50 & 54.00 & 42.50 & 31.00 \\
Median & 1.00 & 0.50 & 0.10 & 0.00 \\
Medium score & 3.62 & 2.70 & 2.12 & 1.55 \\
Fr & 28.18 & & & \\
$\mathrm{p}$ & 0.0001 & & & \\
\hline Multiple comparisons & Difference & $\mathrm{p}$ & & \\
\hline $6 \mathrm{~h} \times 24 \mathrm{~h}$ & 18.50 & $>0.05$ & \\
$6 \mathrm{~h} \times 48 \mathrm{~h}$ & 30.00 & $<0.05$ & & \\
$6 \mathrm{~h} \times 72 \mathrm{~h}$ & 41.50 & $<0.05$ & & \\
$24 \mathrm{~h} \times 48 \mathrm{~h}$ & 11.50 & $>0.05$ & & \\
$24 \mathrm{~h} \times 72 \mathrm{~h}$ & 23.00 & $<0.05$ & \\
$48 \mathrm{~h} \times 72 \mathrm{~h}$ & 11.50 & $>0.05$ & & \\
\hline
\end{tabular}

Table II. Pain intensity scores over the study period for the lumiracoxib group.

\begin{tabular}{lllll}
\hline & \multicolumn{3}{c}{ Period } \\
& 6 hours & 24 hours & 48 hours & 72 hours \\
\hline Scores sum & 64.50 & 53.00 & 42.50 & 40.00 \\
Median & 0.50 & 0.10 & 0.00 & 0.00 \\
Medium score & 3.22 & 2.65 & 2.12 & 2.00 \\
Fr & 11.26 & & & \\
p & 0.0104 & & & \\
\hline Multiple comparisons & Difference & $\mathrm{p}$ & \\
\hline 6h X 24h & 11.50 & $>0.05$ & \\
6h X 48h & 22.00 & $<0.05$ & & \\
$6 \mathrm{~h} \times 72 \mathrm{~h}$ & 24.50 & $<0.05$ & & \\
$24 \mathrm{~h} \times$ 48h & 10.50 & $>0.05$ & \\
$24 \mathrm{~h} \times 72 \mathrm{~h}$ & 13.00 & $>0.05$ & \\
$48 \mathrm{~h} \times 72 \mathrm{~h}$ & 2.50 & $>0.05$ & \\
\hline
\end{tabular}

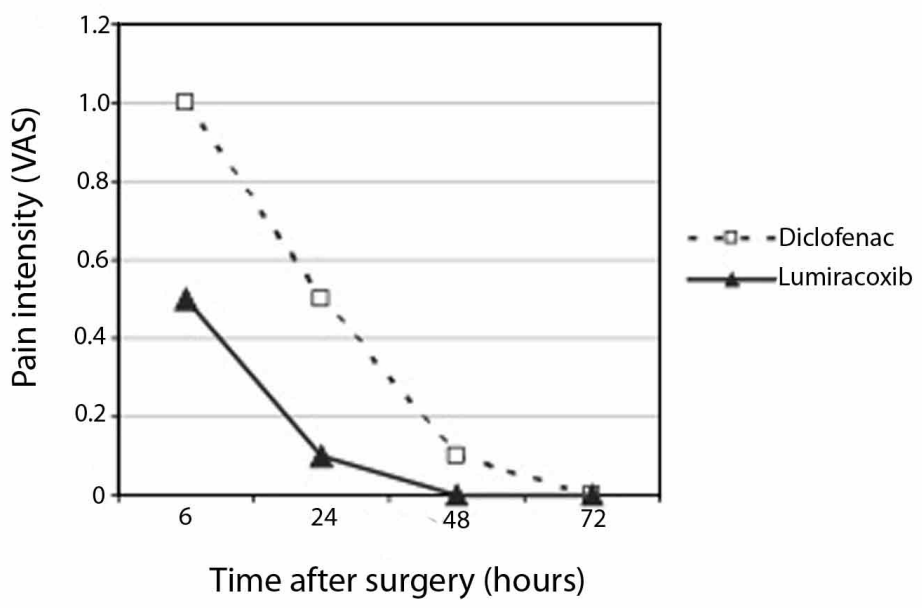

Fig. 1.Pain intensity (VAS) over the study period.
15 to 90 minutes $(42.8 \pm 17.0)$ and all patients had the anesthesia resolved within 6 hours, before observation for pain started.

Concerning about the impaction profile, eight teeth were horizontal $(40.0 \%)$ and vertical $(40.0 \%)$ and four (20.0\%) were mesioangulated, for each side. There were no significant differences between groups in relation to the patient's age and sex, as well as to the teeth position to be extracted.

Regarding to the median for pain for each group, we observed higher pain levels for the diclofenac sodium compared to lumiracoxib group (Fig. 1), however, in both groups, it was reported a progressing pain reducing during time point's measures. Furthermore, in diclofenac sodium (Table I) and lumiracoxib (Table II) groups occurred a statistically significant reduction in postoperative pain levels comparing 6 hours with 48 and 72 hours after surgery. Of note, patients in diclofenac sodium group also reported a significant pain reduction comparing 24 with 72 hours (Table I). The comparison of pain levelsbetween the two anti-inflammatory drugs showed statistically better outcomes for lumiracoxib for the periods of 6,24 and 48 hours, but not for the 72 hour period (Table III).

Table III. Pain intensity scores comparison of both drugs over the study period.

\begin{tabular}{lcc}
\hline Period & $z$ & $p$ \\
\hline 6 hours & -2.5353 & $0.0112^{*}$ \\
24 hours & -2.3541 & $0.0186^{*}$ \\
48 hours & -2.5103 & $0.0121^{*}$ \\
72 hours & -1.4270 & 0.1536 \\
\hline${ }^{*} p<0.05$ & &
\end{tabular}

\section{DISCUSSION}

The development of therapeutic protocols for managing postoperative pain is a relevant issue after third molars surgery, given the more intense pain and inflammatory reaction compared to extraction of erupted teeth. Furthermore, over $90 \%$ of the patients need analgesia 
in the first 12 hours postoperatively. In this context, several papers have been published addressing analgesic effects of NSAIDS, however only three papers investigated lumiracoxib effects in oral surgery settings (Zelenakas et al., 2004; Fricke et al., 2008) and, to the best of our knowledge, this is the first paper to compare this drug efficacy with diclofenac, which is largely utilized in Brazilian dental treatments.

The efficacy of diclofenac as analgesic medication after third molars surgery is a wellestablished issue (Tuzuner Oncul et al.; Akbulut et. al.), which also was confirmed is our paper. However, this drug was associated to worst outcomes compared to others NSAIDS, including aceclofenac (Kollu et al., 2013) and ketoprofen (Velasquez et al., 2014), but no statistically significant differences in analgesic efficacy was described between diclofenac sodium and ibuprofen (Esteller-Martínez et al., 2004), Naproxen and Etodolac (Akbulut et al.). In the present study, diclofenac was choose given its analgesic and antiinflammatory properties, but also due to the low cost and widely distribution by the Brazilian public health system.

Regarding to specific COX-2 inhibitors, including lumiracoxib, the literature also confirm its application to third molar managing postoperative pain (Kellstein et al.; Zelenakas et al.; Fricke et al.), which was also observed in the present paper. The selection of lumiracoxib to this research was due the lack of studies with this drug in oral surgery settings. Furthermore, this drug demonstrated some advantages compared to others specific COX-2 inhibitors, such as fastest onset of analgesia and the longest time to rescue medication use than celecoxib (Kellstein et al.; Zelenakas et al.; Fricke et al.) and better outcomes on the summed (time-weighted) pain intensity difference over the first $8 \mathrm{~h}$ post dose compared to rofecoxib 50 $\mathrm{mg}$ (Kellstein et al.)

Comparing non-selective COX inhibitors with specific COX-2 blockers, different outcomes have been reported. Similar effects were observed between celecoxib and loxoprofen (Yamashita et al., 2014). On the other hand, Zelenakas et al., reported that Lumiracoxib $400 \mathrm{mg}$ produced onset of analgesia in a shorter time than shown by ibuprofen $400 \mathrm{mg}$. In our study, we also observed that Lumiracoxib was more efficient in pain control than diclofenac. The onset occurs in about 37 minutes and persists for up to 24 hours. The difference in effectiveness between the studied drugs decreases with time and is equivalent after 4 days. This is to be expected because the peak in pain occurs between 3 and 12 hours postoperatively (Hyrkas et al., 1994).

Regarding to impaction profile of third molars, differences have been pointed in literature. Some authors stated that the most frequent position of impaction is the mesioangular (Carter, 2015; Mahdey et al., 2015), which is in discordance with our study, since this position corresponds to only $20 \%$ of the teeth that were removed. However, other studies reported that vertical position is the most common observed (Kumar-Pillai et al., 2014; Yilmaz et al., 2015), as we observed in our paper, differing just by the high prevalence of horizontal impaction, which is not commonly reported. These differences in the impaction profile could be due to the race discrepancies, patient selection criteria and study population.

The chronic oral administration of non-selective NSAIDs are linked with many gastrointestinal complications like ulceration, bleeding and perforation (Rafaniello et al.), while highly selective COX-2 inhibitors (coxibs) are associated with an increased risk of adverse cardiovascular events (Patrono, 2016). However, in our study, it was not observed any side effects of NSAIDs, which can be reasonable explained by the absence of previous systemic disease in patients, the short-term drug intake and no other age-related factors.

The study model for dental pain arising from extraction of impacted third molars has been shown to provide a reliable model for determining the short-term efficacy of new drugs (Cooper \& Beaver, 1976). Furthermore, important drug manufacturers have applied it for evaluation of their products (May et al., 2001). However, it is relevant to be stated that standardization is difficult due to several variables, such as experience of the surgeon and pain threshold for the individual patient. Measuring pain is challenging because of the subjectivity, complexity and multiple dimensions involved in the pain experience.

\section{CONCLUSION}

This study demonstrated that both lumiracoxib $400 \mathrm{mg}$ and diclofenac sodium $100 \mathrm{mg}$ are an effective and well-tolerated analgesic for post-operative dental pain after third molars surgery. However, lumiracoxib was associated better outcomes in pain relief on timepoints 6,24 e 48 hours after surgery when compared to diclofenac sodium $100 \mathrm{mg}$. 
NíCOLI, G. A.; CONTE-NETO, N.; CAMPOS, J. Á. D. B.; CABRINI-GABRIELLI, M. A. \& PEREIRA-FILHO, V. A. Eficacia de lumiracoxib frente a diclofenaco de sodio en el control del dolor después de la extracción de un tercer molar inferior impactado. Int. J. Odontostomat., 11(1):47-51, 2017.

RESUMEN: El objetivo de este trabajo fue comparar la eficacia de dos agentes antiinflamatorios distintos, Diclofenaco (Deltaflogin ${ }^{\circledR}$ ) y Lumiracoxib (Prexige ${ }^{\circledR}$ ) en el control del dolor postoperatorio resultante de la extracción quirúrgica de terceros molares inferiores impactados Fueron incluídos, veinte pacientes adultos de la División de Cirugía Oral y Maxilofacial de la Escuela de Odontología de Araraquara, UNESP que presentaron terceros molares inferiores impactados. La extracción de los dientes impactados se realizó en distintos tiempos operatorios a cada lado en un diseño de estudio de boca dividida. Los antinflamatorios evaluados fueron administrados de forma aleatoria en el primer y segundo procedimento quirúrgico. El nivel de dolor se registró utilizando una escala visual análoga a las $6,24,48$ y 72 horas después de la intervención. Ambos; lumiracoxib $400 \mathrm{mg}$ y diclofenaco $100 \mathrm{mg}$ son eficientes para el control del dolor agudo, después de la extracción quirúrgica de terceros molares inferiores impactados. Sin embargo, lumiracoxib ofreció mejor control del dolor.

PALABRAS CLAVE: dolor, terceros molars, agentes antiinflamatorios.

\section{REFERENCES}

Akbulut, N.; Üstüner, E.; Atakan, C. \& Çölok, G. Comparison of the effect of naproxen, etodolac and diclofenac on postoperative sequels following third molar surgery: a randomised, double-blind, crossover study. Med. Oral Patol. Oral Cir. Bucal, 19(2):149-56, 2014.

Bailey, E.; Worthington, H. \& Coulthard, P. Ibuprofen and/or paracetamol (acetaminophen) for pain relief after surgical removal of lower wisdom teeth, a Cochrane systematic review. Br. Dent. J., 216(8):451-5, 2014.

Carter, K. \& Worthington, S. Predictors of third molar impaction: A systematic review and meta-analysis. J. Dent. Res., 95(3):267-76, 2016.

Chunduri, N. S.; Kollu, T.; Goteki, V. R.; Mallela, K. K. \& Madasu K. Efficacy of aceclofenac and diclofenac sodium for relief of postoperative pain after third molar surgery: A randomised open label comparative study. J. Pharmacol. Pharmacother., 4(2):1445, 2013.

Cooper, S. A. \& Beaver, W. I. A model to evaluate mild analgesics in oral surgery outpatients. Clin. Pharmacol. Ther., 20(2):241-50, 1976.

De Menezes, S. A. \& Cury, P. R. Efficacy of nimesulide versus meloxicam in the control of pain, swelling and trismus following extraction of impacted lower third molar. Int. J. Oral Maxillofac. Surg., 39(6):580-4, 2010

Esteller-Martínez, V.; Paredes-García, J.; Valmaseda-Castellón, E.; Berini-Aytés, L. \& Gay-Escoda, C. Analgesic efficacy of diclofenac sodium versus ibuprofen following surgical extraction of impacted lower third molars. Med. Oral Patol. Oral Cir. Bucal, 9(5):448-53, 2004.

Fricke, J.; Davis, N.; Yu, V. \& Krammer, G. Lumiracoxib $400 \mathrm{mg}$ compared with celecoxib $400 \mathrm{mg}$ and placebo for treating pain following dental surgery: a randomized, controlled trial. J. Am. Pain Soc., 9(1):20-7, 2008.

Huskisson, E. C. Visual Analogue Scales Pain Measurement and Assessment. In: Melzak, R. (Ed.). Pain Measurement and Assessment. New York, Raven Press, 1983.

Hyrkäs, T.; Ylipaavalniemi, P.; Oikarinen, V. J. \& Paakkari, I. Effective postoperative pain prevention through administration of bupivacaine and diclofenac. Anesth. Progr., 41(1):6-10, 1994.

Kellstein, D.; Ott, D.; Jayawardene, S. \& Fricke, J. Analgesic efficacy of a single dose of lumiracoxib compared with rofecoxib, celecoxib and placebo in the treatment of post-operative dental pain. Int. J. Clin. Pract., 58(3):244-50, 2004.

Kumar-Pillai, A.; Thomas, S.; Paul, G.; Singh, S. K. \& Moghe, S. Incidence of impacted third molars: A radiographic study in People's Hospital, Bhopal, India. J. Oral Biol. Craniofac. Res., 4(2):76-81, 2014.

Mahdey, H. M.; Arora, S. \& Wei, M. Prevalence and difficulty index associated with the $3(\mathrm{rd})$ mandibular molar impaction among malaysian ethnicities: A clinico-radiographic study. J. Clin. Diagn. Res., 9(9):ZC65-8, 2015.

Mangold, J. B.; Gu, H.; Rodriguez, L. C.; Bonner, J.; Dickson, J. \& Rordorf, C. Pharmacokinetics and metabolism of lumiracoxib in healthy male subjects. Drug. Metab. Dispos., 32(5):566-71, 2004.

Patrono, C. Cardiovascular effects of cyclooxygenase-2 inhibitors: A mechanistic and clinical perspective. Br. J. Clin. Pharmacol., 82(4):957-64, 2016

Rafaniello, C.; Ferrajolo, C.; Sullo, M. G.; Sessa, M.; Sportiello, L.; Balzano, A.; Manguso, F.; Aiezza, M. L.; Rossi, F.; Scarpignato, C. \& Capuano, A. Risk of gastrointestinal complications associated to NSAIDs, low-dose aspirin and their combinations: Results of a pharmacovigilance reporting system. Pharmacol. Res., 104:10814,2016

Tuzuner-Oncul, A. M.; Yazicioglu, D.; Alanoglu, Z.; Demiralp, S.; Ozturk, A. \& Ucok, C. Postoperative analgesia in impacted third molar surgery: the role of preoperative diclofenac sodium, paracetamol and lornoxicam. Med. Princ. Pract., 20(5):470-6, 2011.

Vane, J. R. \& Ferreira, S. H. Handbook of Pharmacology. Berlin, Springer Verlag, 1979

Velasquez, G. C.; Santa-Cruz, L. A. \& Espinoza, M. A. Ketoprofen is more effective than diclofenac after oral surgery when used as a preemptive analgesic: a pilot study. J. Oral Facial Pain Headache, 28(2):153-8, 2011.

Winter, G. B. Impacted Mandibular Third Molars. St. Louis, Med Book, 1926.

Yamashita, Y.; Sano, N.; Shimohira, D.; Danjo, A. \& Goto, M. A. parallelgroup comparison study of celecoxib with loxoprofen sodium in third mandibular molar extraction patients. Int. J. Oral Maxillofac. Surg., 43(12):1509-13, 2014.

Yilmaz, S.; Adisen, M. Z.; Misirlioglu, M. \& Yorubulut, S. Assessment of third molar impaction pattern and associated clinical symptoms in a central anatolian turkish population. Med. Princ. Pract., 25(2):169-75, 2016.

Zelenakas, K.; Fricke, J. R. Jr.; Jayawardene, S. \& Kellstein, D. Analgesic efficacy of single oral doses of lumiracoxib and ibuprofen in patients with postoperative dental pain. Int. J. Clin. Pract., 58(3):251-6, 2004

Corresponding author:

Nicolau Conte-Neto

Department of Oral Surgery

UFPA

Belem

BRAZIL

Received: 12-07-2016

Accepted: 26-12-2016

E-mail: conteneto@hotmail.com 